\title{
Flexural behaviour of reinforced concrete beams with discrete steel - polypropylene fibres
}

\author{
Wan Amizah Wan Jusoh ${ }^{1, *}$, Izni Syahrizal Ibrahim ${ }^{2}$, and Abdul Rahman Mohd Sam ${ }^{3}$ \\ ${ }^{1}$ Department of Structures and Materials, Faculty of Civil Engineering and Environment, UniversitiTun Hussein Onn Malaysia, 26400 \\ Parit Raja, Batu Pahat, Johor, Malaysia \\ ${ }^{2}$ Forensic Engineering Centre, Institute for Smart Infrastructure and Innovative Construction (ISIIC), Faculty of Civil Engineering, \\ Universiti Teknologi Malaysia, 81310 Johor Bahru, Johor, Malaysia \\ ${ }^{3}$ Department of Structures and Materials, Faculty of Civil Engineering, Universiti Teknologi Malaysia, 81310 Johor Bahru, Johor, \\ Malaysia
}

\begin{abstract}
This paper discusses the experimental results on the flexural test of concrete containing different proportions of steel fibre (SF) and polypropylene fibre (PPF). The flexural test was carried out under 4point bending load and followed the relevant standards to FRC. Hooked-end deformed SF fibre with $60 \mathrm{~mm}$ length and fibrillated virgin PPF fibre with $19 \mathrm{~mm}$ length were used in this study. Meanwhile, the concrete was designed for high strength concrete of C60. The mixture included both single SF and PPF, and also the combination of both fibres; Control beam (PC), beam with $75 \% \mathrm{SF}$, beam with $75 \% \mathrm{SF}+25 \% \mathrm{PPF}$ and beam with $25 \% \mathrm{PPF}$. The total fibre volume fraction (Vf) was fixed at $1.5 \%$. The experimental results show that the percentage proportion of combined SF-PPF at $75-25 \%$ had the best performance for its flexural capacity. Mixture with single PPF was also found not effective in delaying the onset of tension cracks and to increase the tensile strength of the concrete. Experimental result also shows beam with $75 \% \mathrm{SF}+25 \% \mathrm{PPF}$ had their structural stiffness improved the most as compared with the others. For the compressive strength, beam with $75 \% \mathrm{SF}+25 \% \mathrm{PPF}$ also revealed comparable performance with the control for high strength composite concrete.
\end{abstract}

\section{Introduction}

Plain concrete is weak in tension because it contains numerous micro cracks. These micro cracks propagate in the concrete matrix under constant applied load. Consequently, plain concrete members cannot sustain tensile stresses developed due to the applied force without the addition of reinforcing elements that are able to withstand these stresses. The addition of randomly distributed discrete fibres to the structural concrete increases its stiffness, ductility and load carrying capacity, while at the same time reduced crack development and propagation. According to the composite material theory and other findings [1], positive synergy of different fibres can complement each other to make new composite material with high performance and good economic benefits [2]-[4]. The use of two or more types of fibres in a suitable combination may potentially improve the overall properties of concrete and resulted in performance synergy [5]-[7]. In this study, steel fibre (SF) and polypropylene fibres (PPF) were combined to produce a hybrid system. Due to the lack of information on the ductile performance of hybrid fibre reinforced concrete composite (HyFRCC), an attempt was made to examine the ductility performance of HyFRCC beams. The presence of one fibre enabled more effective utilization of the potential properties of the other fibre which resulted in improved flexural rigidity, and at the same time controlled thecracking development.

\section{Related previous study}

A study by [8] found that concrete mixed with two different lengths of SF possessed excellent resistance to air blast loading as compared with plain concrete. In their study, the total volume fraction was fixed at $1.5 \%$, with the mixture containing $70 \%$ long and $30 \%$ short hooked-end type steel fibre.

The investigation indicates that the steel fiber reinforced concrete panel containing of $1.5 \%$ volume fraction gave the best performance under explosive loading.In another study by researcher [9], the concrete containing $0.5 \%$ volume fraction of SF not sufficient to provide adequate resistance against blast loading and $1 \%$ of the fibres shows the best performance and significant to reduced hair line cracks on the specimen. Further investigation using three different properties of carbon and polypropylene micro fibres added to steel fibres in a concrete mixture showed that macro fibres of steel with highly deformed geometry produced better hybrid than

* Corresponding author: author@e-mail.org 
those with less deformed geometry [10]. Also, lower volume fraction of fibres had better performance for hybridization than those mixed with high volume fraction.

Flexural behaviour of single and hybrid fibre concrete beams using three types of fibres was previously studied by Sekar and Ramamoorthy [11]. The fibres added in the concrete mixture were the hookedend type SF, polyester recron fibre and coir fibre. Meanwhile, the total volume fraction was applied at $1 \%$. They found that the compressive strength decreases when fibres were presence in the concrete. They also found that the ductility of both SF reinforced beam and hybrid fibre reinforced beam were higher compared with the control (plain). In another study, Sharmila and Thirugnanam [12] examined the significant behaviour of concrete beams added with steel, glass and recron $3 \mathrm{~s}$ fibres under cyclic loading. It was reported that the effect of hybrid fibres influenced the behaviour of the beams by increasing the ductility characteristics by $80 \%$ and energy absorption characteristics by more than $160 \%$. Hybrid fibres also increases energy absorption capacity and therefore an advantageous when applied for structures located at earthquake prone areas.

Besides that, other study evaluated the strengthening method using fibre reinforcement on RC beams [13]. The study found that the flexural behavior of beams strengthened with hybrid fibre reinforcement (sheet or plate) was $60 \%-200 \%$ higher for its reinforcing effect than the non-reinforced beams. These results reflected excellent performance, which was attributed by the combined fibres having high reinforcing effect that leads to stable ductile failure.

Another study on hybrid fibres application revealed that the tensile strength improvement ranging between $25 \%$ and $80 \%$ compared to that of plain concrete [14]. SFs exerted a primary influence in the hybrid system when compared with PPFs. The results indicated that concrete containing PPFs can further improved residual strength in the post-peak response. The study then concluded that concrete containing combined $75 \% \mathrm{SF}+$ $25 \%$ PPF were the most appropriate combination for improved compressive strength, flexural strength and flexural toughness [15].

Hybrid fibre reinforcement of cement composites is rapidly emerging as an innovative and promising way of improving the mechanical performance and durability ofcement-based materials. Previous researchers had carried out study on structural behaviour of glass fibre reinforced polymer (GFRP) concrete hybrid beam [1516]. The studies found that GFRP concrete hybrid beam were presenting reasonable stiffness and also increase the strength of the beam.

\section{Materials and method}

\subsection{Material and mix proportion}

Ordinary Portland Cement (OPC) Type 1 was used in this study. $10 \mathrm{~mm}$ well graded size crushed granite and locally available river sand were used for the coarse and fine aggregates, respectively. The concrete strength was designed based on the DoE method to achieve compressive strength of $60 \mathrm{~N} / \mathrm{mm} 2$ at 28 days, with water-to-cement ratio, w/c fixed at 0.38 . Hooked-end type SF of $60 \mathrm{~mm}$ long and $0.75 \mathrm{~mm}$ diameter was used in this study (see Fig. 1), giving an aspect ratio, 1/d of 80 . Meanwhile, virgin fibrillated type PPF of $19 \mathrm{~mm}$ long was also used as shown in Fig. 2. The properties of both SF and PPF are given in Table 1 and 2, respectively. The mixture was different in proportions based on percentage of: (i) $0 \%$ (control), (ii) $75 \% \mathrm{SF}+25 \% \mathrm{PPF}$, (iii) $75 \%$ $\mathrm{SF}$ and (iv) $25 \%$ PPF. Meanwhile, the total fibre volume fraction, $\mathrm{Vf}$ was fixed at $1.5 \%$. In order to improve concrete workability, superplasticizer was also added in the mixture at dosage rate of $3 \%$ of the cement content. The material proportions for $1 \mathrm{~m} 3$ concrete volume are summarized in Table 3.

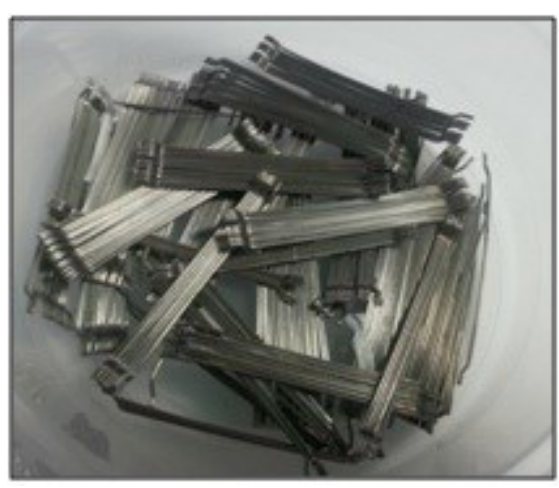

Fig. 1. Steel fibre - hooked end

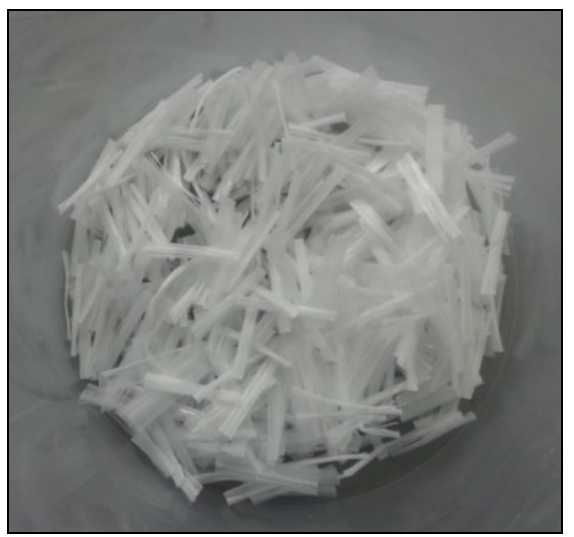

Fig. 2. Polypropylene fibre - fibrillated

\subsection{Beam detail}

A total of four beams with dimension of $275 \mathrm{~mm} \times 380$ $\mathrm{mm} \times 2400 \mathrm{~mm}$ were used in this study. The beams were mixed with various percentage of SF and PPF. All beams were reinforced with 2 nos. of $12 \mathrm{~mm}$ diameter bar at the 
bottom section of the beam (tension zone), while 2 nos. of $8 \mathrm{~mm}$ diameter bar were used as hanger bar (top section).

Table 1. Properties of steel fibre (SF)

\begin{tabular}{|l|c|}
\hline \multicolumn{1}{|c|}{ Parameters } & Capability \\
\hline Type & HE 0.75/60 \\
\hline Shape & Hooked-End (Deformed) \\
\hline Length $(\mathrm{mm})$ & 0.75 \\
\hline Diameter $(\mathrm{mm})$ & 80 \\
\hline Aspect Ratio, $l / d$ & 1100 \\
\hline Tensile Strength $\left(\mathrm{N} / \mathrm{mm}^{2}\right)$ & 7850 \\
\hline Unit Weight $\left(\mathrm{kg} / \mathrm{m}^{3}\right)$ & None \\
\hline Coating & 205000 \\
\hline Elastic Modulus, $E(\mathrm{MPa})$ & \\
\hline
\end{tabular}

Table 2. Properties of of polypropylene fibre (PPF)

\begin{tabular}{|l|c|}
\hline \multicolumn{1}{|c|}{ Parameters } & Capability \\
\hline Type & Virgin PPF \\
\hline Length $(\mathrm{mm})$ & 19 \\
\hline Thickness $(\mathrm{mm})$ & 0.05 \\
\hline Unit Weight $\left(\mathrm{kg} / \mathrm{m}^{3}\right)$ & 446 \\
\hline Tensile Strength $\left(\mathrm{N} / \mathrm{mm}^{2}\right)$ & 400 \\
\hline Thermal Conductivity & Low \\
\hline Elastic Modulus, $E(\mathrm{MPa})$ & 3500 \\
\hline
\end{tabular}

Table 3. Material proportions for $1 \mathrm{~m}^{3}$ concrete volume

\begin{tabular}{|c|c|c|c|c|c|c|c|}
\hline E & 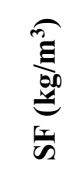 & 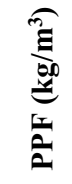 & 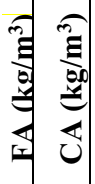 & 竞 & 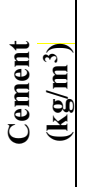 & $\frac{e}{3}$ & \\
\hline Control & - & - & 794 & 210 & 522 & 0.38 & 3 \\
\hline $75 \% \mathrm{SF}$ & 88.3 & & 794 & 210 & 522 & 0.38 & 3 \\
\hline $\begin{array}{l}75 \% \mathrm{SF}+ \\
25 \% \mathrm{PPF}\end{array}$ & 88.3 & 1.67 & 794 & 210 & 522 & 0.38 & 3 \\
\hline $25 \% \mathrm{PPF}$ & - & 1.67 & 794 & 210 & 522 & 0.38 & 3 \\
\hline
\end{tabular}

Notations:

$S F-$ Steel Fibre

PPF-Polypropylene fibre

FA- Fine Aggregate

$C A$ - Coarse Aggregate

w/c-Water-to-cement ratio

SP-Superplasticizer

\subsection{Beam instrumentation and testing}

All beams were tested under four point loading systemusing a $500 \mathrm{kN}$ testing machine capacity. The beams were simply supported over a span of $1200 \mathrm{~mm}$. The distance between the two point loads was kept a part at $150 \mathrm{~mm}$ symmetrical to the centerline of the beam. Loading was applied using a hydraulic jack at the rate of $2 \mathrm{kN} / \mathrm{s}$ until failure. Mid-span deflection was measured for every $2 \mathrm{kN}$ loading increment using Linear Variable Displacement Transducer (LVDT) with $0.01 \mathrm{~mm}$ accuracy. The deflection of the beam was measured at three points along the beam span; mid-span and $1 \mathrm{~m}$ from left and $1 \mathrm{~m}$ from right supports. The beams were instrumented with embedded and external strain gauges to monitor the concrete and steel strains at different loading stages. Concrete strain gauges were installed on the beam surface, while steel strain gauges were attached at the top and bottom of the longitudinal reinforcing bars, also at mid-span. Both the electrical concrete and steel strain gauges were installed at mid-span section of the beam, where maximum bending moment was to occur. At each loading increment, deflection and strains were recorded using a data logger. At the same time, cracking development was also observed and monitored closely. The loading arrangement and instrumentation of the flexural beam test is shown in Fig. 3 .

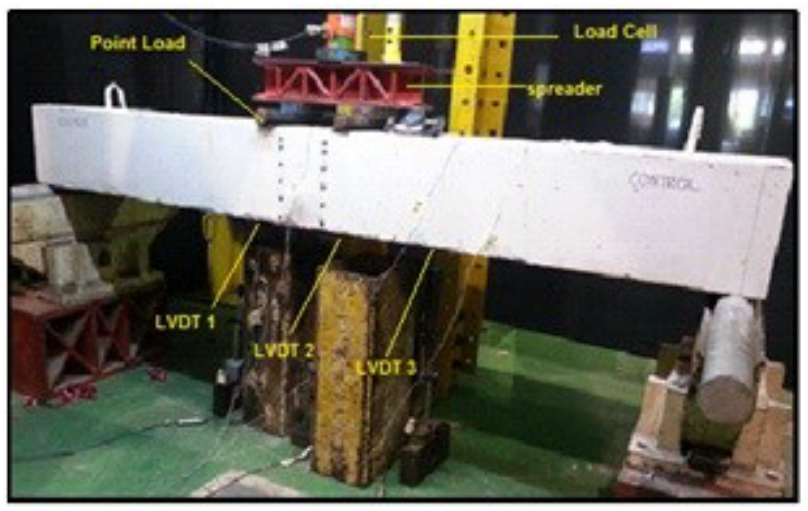

Fig. 3. Test set-up

\section{Results}

Flexural test was carried out on beams with varies mix proportion of SFs and PPFs as discrete reinforcement in a concrete mixture. To characterize the flexural performance and behaviour of the beams, analysis and discussion were done on its ultimate load, loaddeflection behavior, load-strain behavior and cracking pattern.

\subsection{Ultimate load on reinforced concrete}

The result of the first crack load and ultimate load for all beams are summarized in Table 4 together with the compressive strength of the concrete. The compressive strength at 28 dayswas $60.3 \mathrm{~N} / \mathrm{mm}^{2}, 68.7 \mathrm{~N} / \mathrm{mm}^{2}, 66.5$ $\mathrm{N} / \mathrm{mm}^{2}$ and $60.0 \mathrm{~N} / \mathrm{mm}^{2}$ for control beam, beams with $75 \% \mathrm{SF}, 75 \% \mathrm{SF}+25 \% \mathrm{PPF}$ and $25 \% \mathrm{PPF}$, respectively. 
The table shows that the addition of fibres increased the load carrying capacity for all beams. The ultimate load for the control beam, beams with $75 \% \mathrm{SF}, 75 \% \mathrm{SF}+$ $25 \% \mathrm{PPF}$ and $25 \% \mathrm{PPF}$ were $77.4 \mathrm{kN}, 97.1 \mathrm{kN}, 97.7 \mathrm{kN}$ and $70.2 \mathrm{kN}$, respectively. The finding also shows that the ultimate load carrying capacity was more significant for beam with $75 \% \mathrm{SF}+25 \% \mathrm{PPF}$. In this study, the ultimate load for beam with $75 \% \mathrm{SF}+25 \% \mathrm{PPF}$ produced the highest ultimate load followed by beam with $75 \% \mathrm{SF}$, showing an increase of $25 \%$ and $26 \%$ from the control. Meanwhile, beam with $25 \%$ SF obtained the lowest load carrying capacity which was even lower than the control ( $0 \%$ fibre). The high ultimate loading capacity for beams $75 \% \mathrm{SF}+25 \% \mathrm{PPF}$ and $75 \% \mathrm{SF}$ was due to the sufficient bridging action of the steel fibres that prevent the crack from further expanding during the test. This is because the characteristics of SF include higher Elastic Modulus and tensile strength, and ductile in flexural mode before failure. PPF will encounter for micro cracks while SF encountered for macro cracks. The hooked end type SF also give some advantage in delaying macro cracks by gripping the particles inside concrete and bridging crack growth before failure. Meanwhile, the ultimate loading capacity of beam with $25 \%$ PPF was $9.3 \%$ lower than the control beam. In the case of PPF, the beam was attributed for arresting non-structural crack such as shrinkage crack. PPF can be used as secondary reinforcement in concrete to reduce cracking and benefit for large surface area construction such as floor slab and tunnel lining[18]-[20].

Table 4. Test results

\begin{tabular}{|c|c|c|c|c|c|}
\hline 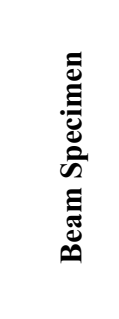 & 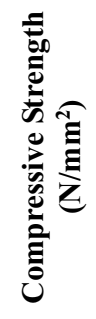 & 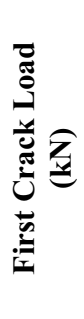 & 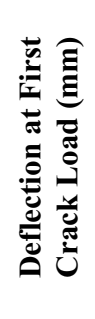 & 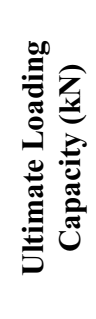 & 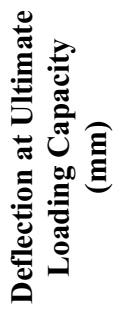 \\
\hline Control & 60.3 & 30 & 0.76 & 77.4 & 68.44 \\
\hline $75 \% \mathrm{SF}$ & 68.7 & 46 & 1.16 & 97.1 & 16.97 \\
\hline $\begin{array}{c}75 \% \mathrm{SF} \\
+ \\
25 \% \mathrm{PPF}\end{array}$ & 66.5 & 50 & 1.32 & 97.7 & 6.93 \\
\hline $25 \% \mathrm{PPF}$ & 60.0 & 34 & 0.66 & 70.2 & 23.1 \\
\hline
\end{tabular}

\subsection{Load - deflection response}

Load-deflection relationship for all beams is shown in Fig. 4. Control beam was used to compare and discuss the result for other beams with $75 \% \mathrm{SF}, 75 \% \mathrm{SF}+$ $25 \% \mathrm{PPF}$ and $25 \% \mathrm{PPF}$. As concrete weak in tension, the first tension crack occurred near the mid span region (maximum bending moment region). The number of cracks increase as the load was further increased. The load-deflection patterns for all beams at different locations are shown in Fig. 4(a), 4(b) and 4(c).

Generally, the load-deflection curves can be classified to three distinct zones; the first zone is the initial part of the curve to the cracking point, the post cracking zone, continued to the yielding point and the post yield zone, up to failure. At the initial stage the beams stiffness showed almost identical at low level of loading and up to the cracking load as this stage is controlled mainly by the concrete tensile strength The average of load and deflection curve for $75 \% \mathrm{SF}$ and $75 \% \mathrm{SF}+25 \% \mathrm{PPF}$ proved higher stiffness compared to $25 \% \mathrm{PPF}$ and control beam. The second zone, showed a distinct behavior in the different beams. The slope of the curve is a direct function represents the effective stiffness of the beam. Last part of the post yield zone, the beams showed the ability to withstand higher load in different rates and to gain more deformability until failure.

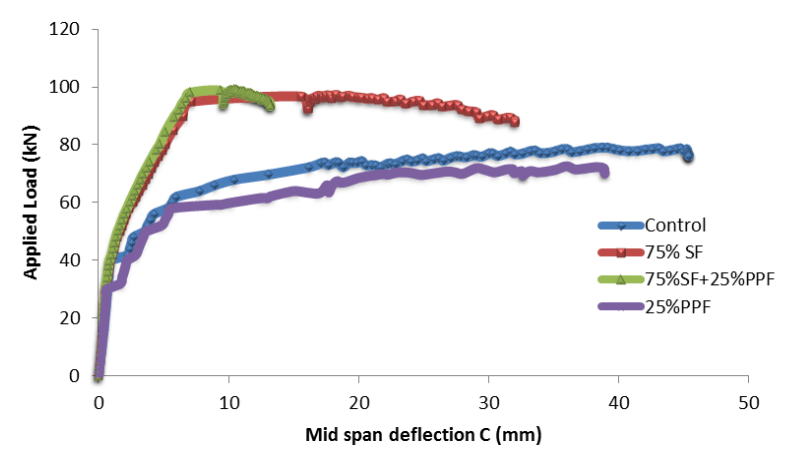

(a) Load-deflection at midspan

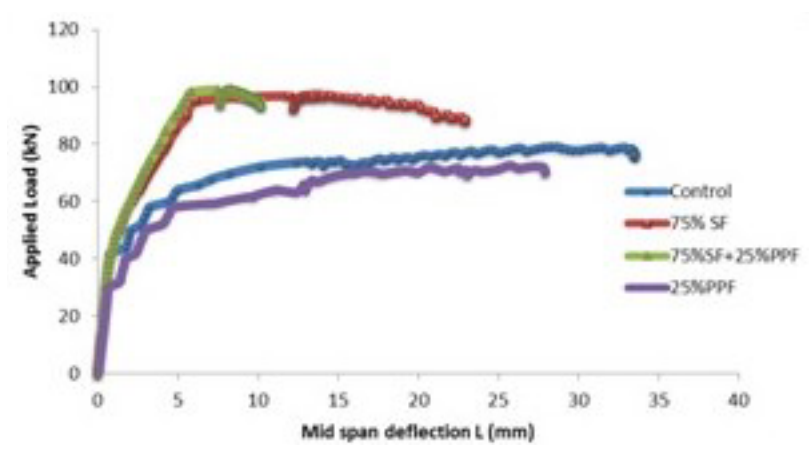

(b) Load-deflection at left of span

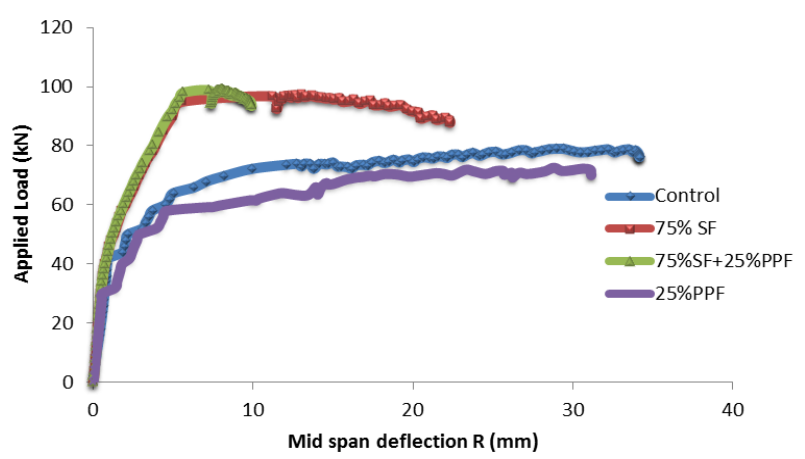

(c) Load-deflection at right of span

Fig. 4. Load-deflection relationship

\subsection{Load - strain of reinforced concrete beam}

Figure 5 show the load-strain behavior of the beams based on the compression zone. The behavior also 
indicates that the control beam behaved in brittle manner after loads of $40 \mathrm{kN}$ was reached while beams with $75 \% \mathrm{SF}$ and $75 \% \mathrm{SF}+25 \% \mathrm{PPF}$ behaved in ductile manner.

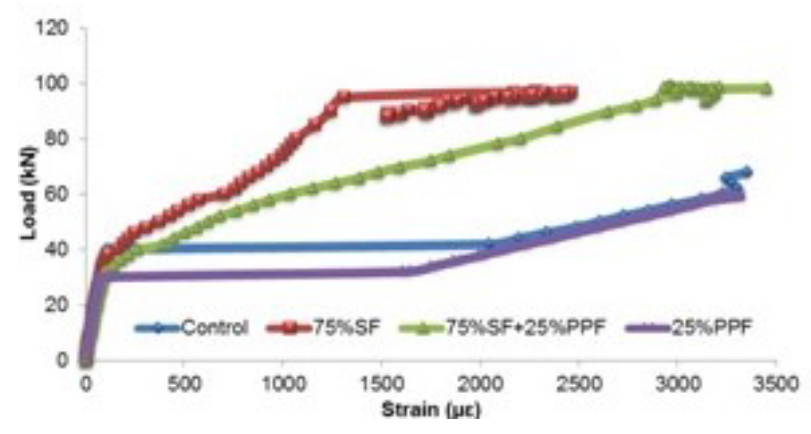

Fig. 5. Load $(\mathrm{kN})$ versus strain $(\mu \varepsilon)$ for control beam

Table 5 shows the maximum compressive strain at structural failure. Generally, the maximum compressive strain in the concrete is 0.0035 , and the compressive strain for control beam in this study achieved that almost maximum compressive strain. However, the maximum compressive strain for beam with $75 \% \mathrm{SF}, 75 \% \mathrm{SF}$ lower value than that of control beam with $0.0022,0.0029$ and $25 \%$ PPF obtained almost maximum with 0.0032 respectively but the difference between them were small. The ranges of maximum compressive strain for beam $75 \% \mathrm{SF}, 75 \% \mathrm{SF}$ lower observed from this study were from 0.0020 to 0.0029 and beam with $25 \% \mathrm{PPF}$ observed 0.0029-0.0032.

Table 5. Maximum compressive strain for control and RC beams with fibres

\begin{tabular}{|c|c|}
\hline Type of Beam & Maximum compressive strain, $\boldsymbol{\varepsilon}$ \\
\hline Control (PC) & 0.0033 \\
\hline $75 \% \mathrm{SF}$ & 0.0022 \\
\hline $75 \% \mathrm{SF}+25 \% \mathrm{PPF}$ & 0.0029 \\
\hline $25 \% \mathrm{PPF}$ & 0.0031 \\
\hline
\end{tabular}

\subsection{Cracking and failure mode}

All beams failed in flexure with cracking developed at the tension zone as shown in Fig. 6. It was observed that all beams developed fine cracks from the end at the tension zone under a relatively small load of about $30-$ $40 \%$ of their ultimate load. The first noticeable crack was formed between the locations of the midspan followed by two point loads in the region of maximum bending moment. From Fig. 5, as the beam's ductility increases, more hairline cracks appeared in the flexural zone. Beam with $75 \% \mathrm{SF}+25 \% \mathrm{PPF}$ had a total of 10 cracking line compared to only 8 lines for beam with $75 \%$ SF. Meanwhile, for beam with $25 \% \mathrm{PPF}, 6$ crack lines were found as compared with only 4 lines for the control beam. The number given along each crack represents the load at which the crack was extended. This shows that by combining fibres with different properties, they are more capable to resist higher load and reduced crack opening at ultimate load. This is because the bridging effect of both SF and PPF to arrest crack development and propagation during the early stage of concrete casting (wet) and hardening (dry) process enhanced the structural performance of the beam. For control beam and beam with $25 \% \mathrm{PPF}$, it can resist lower ultimate loading capacity with lesser cracks than beams with $75 \% \mathrm{SF}$ and $75 \% \mathrm{SF}+25 \% \mathrm{PPF}$. The crack width at ultimate load was recorded at $2.48 \mathrm{~mm}$, $0.40 \mathrm{~mm}, 0.60 \mathrm{~mm}$ and $1.80 \mathrm{~mm}$ for control beam, beams with $75 \% \mathrm{SF}+25 \% \mathrm{PPF}, 75 \% \mathrm{SF}$ and $25 \% \mathrm{PPF}$, respectively. Table 6 summarized the number of cracks, crack spacing and depth for all beams at ultimate load.

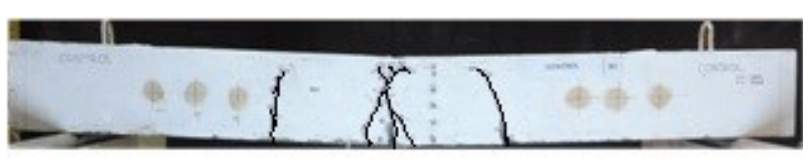

(a) Control (PC)

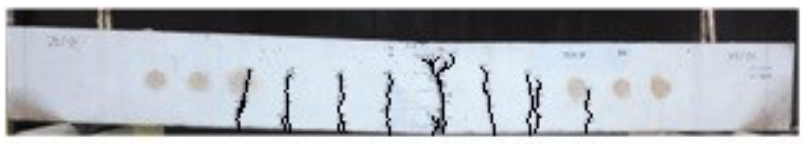

(b) $\mathrm{RC}+75 \% \mathrm{SF}$

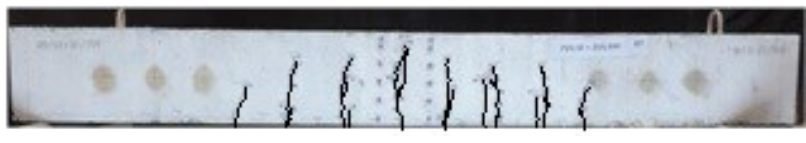

(c) $\mathrm{RC}+75 \% \mathrm{SF}+25 \% \mathrm{PPF}$

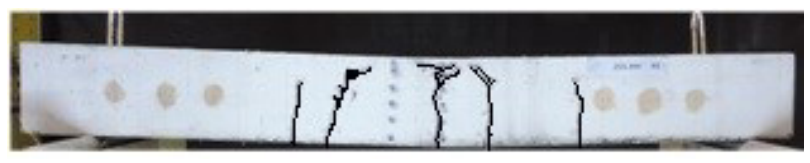

(d) $\mathrm{RC}+25 \% \mathrm{PPF}$

Fig. 6. Failure mode of OPC concrete beam

Table 6. Structural failure mode

\begin{tabular}{|c|c|c|c|}
\hline Beams & $\begin{array}{c}\text { Number of } \\
\text { Cracks }\end{array}$ & $\begin{array}{c}\text { Average } \\
\text { Crack Spacing } \\
\text { (mm) }\end{array}$ & $\begin{array}{c}\text { Crack } \\
\text { Depth (cm) }\end{array}$ \\
\hline $\begin{array}{c}\text { Control } \\
\text { (PC) }\end{array}$ & 4 & 19.8 & 34.3 \\
\hline $75 \% \mathrm{SF}$ & 8 & 11.2 & 20.6 \\
\hline $\begin{array}{c}75 \% \mathrm{SF}+ \\
25 \% \mathrm{PPF}\end{array}$ & 10 & 12.2 & 19.2 \\
\hline $25 \% \mathrm{PPF}$ & 6 & 13.6 & 20.4 \\
\hline
\end{tabular}

\section{Conclusions}

1. The crack pattern of beams for all beams shows it's failed in flexural zone. The number of cracks increased and they show better distributed especially in beams $75 \% \mathrm{SF}+25 \% \mathrm{PPF}$ indicating higher ductility of the beam.

2. Beam with $75 \% \mathrm{SF}+25 \% \mathrm{PPF}$ had the highest 
structural stiffness of 32\% compared with the control beam. Meanwhile, beams with $75 \%$ SF and $25 \% \mathrm{PPF}$ increased by $29 \%$ and $7 \%$, respectively for its flexural strength.

3. The ultimate load capacity and stiffness of the beams increased when SF and PPF were added together in a single mixture. This indicates that both properties were a good combination for structural applications. However, adding PPF only was not suitable for structural purposes.

4. Vertical cracks appeared during the initial load until the beams failed. The crack opening and propagation increases when the applied load was further increased.

This research was funded by the Research University Grant (RUG) No. 09H36. Invaluable appreciation goes to all staffs and Assistant Engineers in the Structures and Materials Laboratory, Faculty of Civil Engineering and Faculty of Chemical, UniversitiTeknologi Malaysia (UTM). Special acknowledgment also goes to the Ministry of Higher Education Malaysia (MoHE) and UniversitiTun Hussein Onn Malaysia (UTHM) for the scholarship sponsored throughout the study.

\section{References}

1. N. Banthia, R. Gupta, Mater. Struct., 37, 707-716 (2004)

2. C. X. Qian, P. Stroeven, Cem. Concr. Res., 30, 63-69 (2000)

3. S. P. Singh, A. P. Singh, and V. Bajaj, Asian J. Civ. Eng., 11, 495-507 (2010)

4. P. Wang, Z. Huang, J. Jiang, Y. Wu, Am. Soc. Civ. Eng., 11, 677-683 (2012)

5. M. Hsie, C. Tu, P. S. Song, Mater. Sci. Eng. A, 494, 153157 (2008)

6. J. S. Lawler, D. Zampini, S. P. Shah, J. Mater. Civ. Eng., 17, 595-604 (2005)

7. L. Sorelli, N. Banthia, G. A. Plizzari, J. Am. Concr. Inst., 224, 161-178 (2004)

8. M. A. Yusof, N. M. Nor, A. Ismail, N. C. Peng, R. M. Sohaimi, M. A. Yahya, Adv. Mater. Sci. Eng., 13, 1-7 (2013)

9. M. A. Yusof, N. M. Nor, M. Fauzi, M. Zain, N. C. Peng, A. Ismail, R. M. Sohaimi, A. Mujahid, A. Zaidi, Concrete, 7, 159-166 (2011)

10. N. Banthia, M. Sappakittipakorn, Cem. Concr. Res., 37, 1366-1372 (2007)

11. C. Sekar, N. Ramamoorthy, Int. J. Eng. Res. Technol., 2, 2148-2157 (2013)

12. S. Sharmila, G. Thirugnanam, Int. J. Sci. Environ. Technol., 2, 725-734 (2013)

13. S.T. Yi, S. G. Cho, Proc. ICE - Struct. Build., 166, 537$546(2013)$

14. L. Xu, L. Huang, Y. Chi, G. Mei, ACI Struct. J., 113, 219$230(2016)$

15. S. P. Singh, A. P. Singh, V. Bajaj, Asian J. Civ. Eng., 11, 495-507 (2010)

16. M. D. Krall, Tests on Concrete Beams with GFRP Flexural and Shear Reinforcements and Analysis Method for Indeterminate Strut-and-Tie Models with Brittle Reinforcements, Master Thesis , University of Waterloo, Canada, 2014

17. C. E. Bakis, L. C. Bank, V. L. Brown, E. Cosenza, J. F. Davalos, J. J. Lesko, A. Machida, S. H. Rizkalla, T. C. Triantafillou, J. Compos. Constr., 62, 73-87 (2002).
18. P.K.R. Dilip, J. Softw. Hardw. Res. Eng., 23, 47-51 (2014)

19. S. K. Verma, M. Dhakla, A. Garg, Int. J. Eng. Innov. Technol., 4, 10, 90-94 (2015)

20. A. E. Yurtseven, Determination of mechanical properties of hybrid fiber einforced concrete, Master Thesis, Middle East Technical University, 2004 